\title{
Tunable Phosphatase-Sensitive Stable Prodrugs of 5-aminolevulinic acid for Tumor Fluorescence Photodetection
}

\author{
Andrej Babič*, Viktorija Herceg, Imene Ateb, Eric Allémann and Norbert Lange \\ School of Pharmaceutical Sciences, University of Geneva, University of Lausanne, 1211 Geneva, Switzerland
}

Keywords: 5-aminolevulinic acid, prodrugs, alkaline phosphatase, tumor photodetection, photodynamic therapy

\begin{abstract}
5-aminolevulinic acid (5-ALA) has been at the forefront of small molecule based fluorescence-guided tumor resection and photodynamic therapy. 5-ALA and two of its esters received marketing authorization but suffer from several major limitations, namely low stability and poor pharmacokinetic profile. Here, we present a new class of 5-ALA derivatives aiming at the stabilization of 5-ALA by incorporating a phosphatase sensitive group, with or without self-cleavable linker. Compared to 5-ALA hexyl ester (5-ALA-Hex), these compounds display an excellent stability under acidic, basic and physiological conditions. The activation and conversion into the 5-ALA is controlled and can be structure-tailored. The two classes of prodrugs display reduced acute toxicity compared to 5-ALA-Hex with superior dose response profiles of protoporphyrin IX synthesis and fluorescence intensity in human glioblastoma cells in vitro. Clinically relevant fluorescence kinetics in vivo shown in U87Mg glioblastoma spheroid tumor model in chick embryos provide a solid basis for their further development and translation to clinical fluorescence guided tumor resection and photodynamic therapy.
\end{abstract}

\section{Introduction}

5-aminolevulinic acid (5-ALA) is a natural precursor of protoporphyrin IX (PpIX) in heme biosynthesis (Figure 1). Exogenous administration of 5-ALA causes temporary overproduction and accumulation of fluorescent PpIX by circumventing the negative feedback mechanism of heme biosynthesis [1]. Preferential accumulation of PpIX in rapidly proliferating cells as compared to healthy cells provides excellent inherent selectivity. This gives 5-ALA great potential for use in fluorescence photodetection (FPD) [2, 3], fluorescence-guided tumor resection (FGR) [4, 5], sono- (SDT) [6, 7] and photodynamic therapy (PDT) [8, 9]. In this respect 5-ALA is an exceptional molecule as there have been only a handful of small molecules successfully used for these purposes [10].

The overwhelming clinical need for better detection and treatment options is perhaps best exemplified by malignant gliomas [11], a group of highly aggressive brain neoplasms characterized by an extremely infiltrative growth and median survival rate of 15 months [12]. The optimal treatment option for glioma patients is the complete resection of malignant tissue followed by adjuvant radiotherapy and chemotherapy [13]. However, complete tumor resections often fail because of undistinguishable differences between tumors and the surrounding healthy tissue during surgery. To address this issue, 5ALA-induced PpIX fluorescence was tested for FGR in malignant gliomas and proved effective in clinical trials [14]. Today, 5-ALA is approved and commercialized under the tradename of Gliolan ${ }^{\circledR}[15]$ despite the fact that only $0.1 \%$ of the administered dose reaches the brain.

*Corresponding author: University of Geneva, University of Lausanne, School of Pharmaceutical Sciences, Pharmaceutical Technology, 30 Quai E. Ansermet, CH-1211 Geneva, Switzerland. Tel. +41 22379 36 78, Fax. +41 223796567.

E-mail address: andrej.babic@unige.ch 


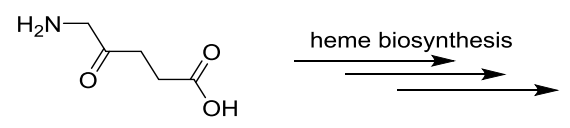

ALA

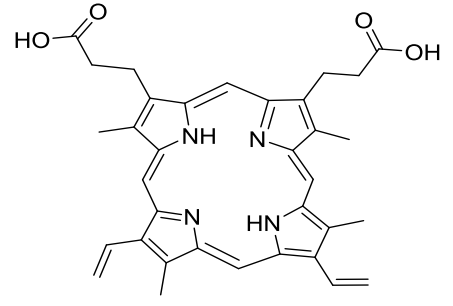

PpIX

Fig 1. Exogenous applications of non-fluorescent 5-ALA leads to the accumulation of fluorescent PpIX in cancer cells.

The latter can be explained by 5-ALA's poor bioavailability caused by its zwitterionic character under physiological conditions. The resulting polarity, thus, limits 5-ALA's ability to pass biological barriers. This, along with its short half-life, small volume of distribution and accumulation in the liver and kidneys [16], makes 5-ALA non suitable for systemic administration [17]. To overcome these shortcomings, different strategies aimed at improving the drug-likeness and the pharmacokinetic profile have been employed. An optimal clinical outcome can be expected when a balance is reached between the stability of the molecule, ability to pass biological barriers, passive or active entry [18], low toxicity, and most importantly efficient induction of PpIX-mediated fluorescence.

Until today, research on improving 5-ALA-induced PpIX focused increasing 5-ALA's lipophilicity mostly through the modifications of carboxylic group of 5-ALA resulting in a vast variety of structurally diverse esters [19]. The major reasoning is that increased lipophilicity potentially improves the passage through biological membranes thus increasing intracellular substrate concentration for heme biosynthesis.

The only clinically implemented solution to improve 5-ALA remains a simple esterification of the 5-ALA's carboxylic group with aliphatic alcohols. 5-ALA-methyl ester (Metvix $®)$ is approved for the topical treatment of actinic keratosis and basal cell carcinoma [9], and ALA-Hex (Hexvix $\left.{ }^{\circledR}\right)$ has been marketed for the FPD of bladder cancer [19]. Although improved in the terms of lipophilicity and permeability, ALA-Hex is acutely toxic with equally poor pharmacokinetic profile as 5-ALA hence not providing a potential alternative for systemic administration $[17,20]$.

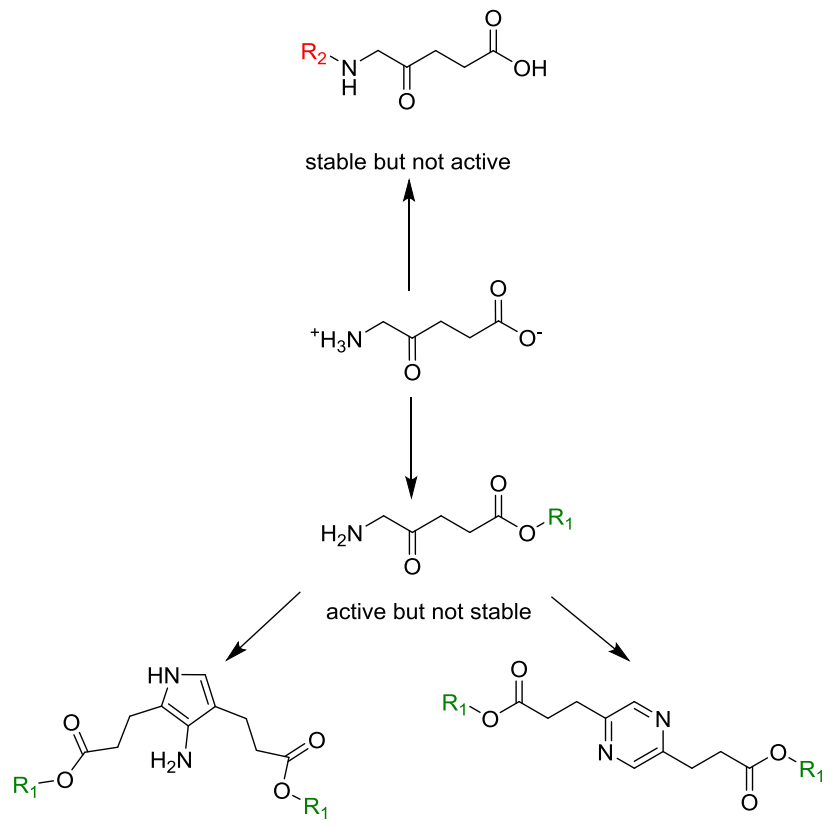

Fig. 2. The stability-activity paradox of ALA. Free 5-amino ALA and its ester derivatives (R1) have improved properties but low stability at physiological pH. Derivatization of the amino group of ALA (R2) results in stable ALA products that have greatly diminished or no pharmacological activity. 
The additional drawback of 5-ALA derivatives with unprotected 5-amino group is their inherent chemical instability. At physiological $\mathrm{pH}$ they undergo irreversible degradation to 3,3'-(3-amino-1H-pyrrole-2,4-diyl)dipropionic acid derivatives and predominantly 2,5-( $\beta$-carboxyethyl) dihydropyrazine followed by oxidation to fully aromatic 2,5-( $\beta$ carboxyethyl)pyrazine (Figure 2). This interferes with the formation of porphobilinogen which is the biological result of enzymatically catalyzed asymmetrical 5-ALA condensation [21, 22]. This adds to the complexity for the clinical use of 5ALA and its derivatives since the pharmacological response will vary according to $\mathrm{pH}$, buffer composition, concentration, and the timeframe between the preparation of the pharmaceutical form and its use [22]. The obvious chemical solution to this problem is the protection of 5-ALA's terminal amino group. On the other hand, the introduction of most groups at the 5amino its end either greatly reduces or completely diminishes pharmacological activity. To the best of our knowledge, the only exception is a series of pseudodipeptides conjugated to 5-ALA's which induced the PpIX production in only limited number of cancer cell lines [23-25].

Albeit endowed with poor physico-chemical properties the limited clinical success of 5-ALA and its ester derivatives provides a proof of the translational potential for new 5-ALA prodrugs that manage to overcome these drawbacks. Since 5ALA-induced PpIX is selective for tumors, we hypothesized that the introduction of an N-terminal group that can be activated by ubiquitously expressed enzymes would circumvent this problem. Therefore, we have focused our efforts on the design and synthesis of novel classes of 5-ALA derivatives modified at the amino group that can be activated in vivo by alkaline phosphatases [26], ubiquitous enzymes present in all tissues and known to be overexpressed in certain types of tumors [27-30]. To the best of our knowledge this is the first time that the 5-amino group has been successfully protected using a phosphate group. These modifications hold promise to overcome barriers for systemic administration of conventional 5-ALA esters. .

\section{Materials and Methods}

Chemicals were purchased from Sigma-Aldrich and Acros and used as received. Ultrapure water was prepared using a Millipore MilliQ Advantage A10 System (Millipore, Bedford, USA). Alkaline phosphatase from calf intestine was obtained from Applichem (AxonLab AG, Switerland). Buffers were freshly prepared according to standard Geigy buffer tables. Reactions were performed under inert argon conditions. Dry dichloromethane $(\mathrm{CH} 2 \mathrm{Cl} 2)$ was freshly distilled over $\mathrm{CaH} 2$ under nitrogen. Dry tetrahydrofuran (THF) was distilled from sodium/ benzophenone under nitrogen. Analytical thin layer chromatography was performed using TLC Silica gel $60 \mathrm{~F}_{254}$ alumina plates and visualized at $254 \mathrm{~nm}$ and $366 \mathrm{~nm}$.

\subsection{Purification}

Normal phase Flash chromatography was done using PuriFlash 4100 system from Interchim (Montluçon , France) equipped with a diode array detector and fraction collector. Preparative reverse-phase HPLC was performed on PuriFlash 4100 system from Interchim or Water delta 600 HPLC system equipped with Water 2487 dual wavelength detector and Macherey Nagel Nucleodur C18-Htec $5 \mu \mathrm{m} 250 \times 21 \mathrm{~mm}$ semi-preparative column or Waters Symmetry C4 $5 \mu \mathrm{m}, 19 \times 150 \mathrm{~mm}$ semipreparative column.

\subsection{Characterization}

UPLC-MS analyses were performed using Thermo Fisher Accela system and Macherey Nagel C18 Nucleodur Gravity 1.8 $\mu \mathrm{m} 50 \times 2 \mathrm{~mm}$ UPLC columns. ${ }^{1} \mathrm{H},{ }^{13} \mathrm{C},{ }^{31} \mathrm{P}, \mathrm{COSY}, \mathrm{HMBC}$ and HSQC NMR spectra were acquired at $298 \mathrm{~K}$ on Varian Anova $300 \mathrm{MHz}$ and Agilent Varian Inova $500 \mathrm{MHz}$ NMR spectrometer (Palo Alto, CA, USA)500 MHz spectrometers at the School of Pharmaceutical Sciences and Bruker Avance 300 and Bruker Cryo-Avance III $500 \mathrm{MHz}$ spectrometers at the Chemistry NMR facility at the University of Geneva, Switzerland. All chemical shifts are reported in the standard notation of parts per million using the peak of residual proton and carbon signals of the solvent as internal references. NMR peaks are referred to as singlet (s), doublet (d), doublet of doublets (dd), triplet (t), broad singlet (br s), or multiplet (m). Coupling constants $(J)$ are reported in Hertz. Low-resolution mass spectroscopy using electrospray ionization (ESI) were performed on API 150EX from AB/MDS Sciex. High-resolution mass spectroscopy measurements were performed on QSTAR Pulsar XL from AB/MDS Sciex. Chemical structures were drawn and named according IUPAC nomenclature using ChemBioDraw version 14.0.0.117 software package. NMR spectra were processed with Mnova version 8.0.2 software package.

\subsection{Synthesis}

\subsubsection{Hexyl 5-amino-4-oxopentanoate 1}

Hexyl 5-amino-4-oxopentanoate was synthesized according to published procedure [31]. Briefly, thionyl chloride (8.20 g, $68.9 \mathrm{mmol})$ was added dropwise to 1-hexanol $(60.0 \mathrm{~mL}, 48.8 \mathrm{~g}, 475 \mathrm{mmol})$ in an ice-bath. After the solution was stirred for 
10 min the ice-bath was removed, 5-aminolevulinic acid hydrochloride $(8.20 \mathrm{~g}, 49.0 \mathrm{mmol})$ was added. The reaction mixture was stirred at ambient temperature for $1 \mathrm{~h}$, followed by reflux at $80^{\circ} \mathrm{C}$ for $2 \mathrm{~h}$. After cooling down, ether $(150 \mathrm{~mL})$ was added and the precipitate filtered off and washed with ether $(2 \times 50 \mathrm{~mL})$. Extensive drying in vacuo gave colorless solid (10.6 g, 42.1 mmol, 86\%).

${ }^{1} \mathrm{H}$ NMR (300 MHz, DMSO-d6) $\delta 8.35(\mathrm{~s}, 3 \mathrm{H}), 3.97(\mathrm{t}, J=6.7 \mathrm{~Hz}, 2 \mathrm{H}), 3.92(\mathrm{~s}, 2 \mathrm{H}), 2.78(\mathrm{t}, J=6.5 \mathrm{~Hz}, 2 \mathrm{H}), 2.52(\mathrm{t}, J=6.5$ $\mathrm{Hz}, 2 \mathrm{H}), 1.61-1.43(\mathrm{~m}, 2 \mathrm{H}), 1.37-1.14(\mathrm{~m}, 2 \mathrm{H}), 1.05-0.73(\mathrm{~m}, 1 \mathrm{H}) .{ }^{13} \mathrm{C}$ NMR $(75 \mathrm{MHz}, \mathrm{DMSO}-d 6) \delta 203.33,172.74$, 64.77, 47.19, 34.94, 31.55, 28.72, 27.76, 25.68, 22.67, 14.58. LRMS, ESI: $\mathrm{m} / \mathrm{z} 216.4[\mathrm{M}+\mathrm{H}]^{+}$. HRMS: $\mathrm{m} / \mathrm{z}$ calculated for C11H22NO3 216.1594 [M] ${ }^{+}$, observed 216.1597.

\subsubsection{Hexyl 5-(((chloromethoxy)carbonyl)amino)-4-oxopentanoate 2}

$1(251.0 \mathrm{mg}, 1.00 \mathrm{mmol})$ was dissolved in dry DCM $(20.0 \mathrm{~mL})$ and cooled to $-20{ }^{\circ} \mathrm{C}$ under argon atmosphere. Chloromethyl chloroformate $(141.8 \mathrm{mg}, 1.10 \mathrm{mmol})$ was added under stirring in one portion followed by dropwise addition of triethylamine $(417 \mu \mathrm{L}, 3.00 \mathrm{mmol})$ dissolved in dry DCM $(5.0 \mathrm{~mL})$. The reaction mixture was stirred for $1 \mathrm{~h}$ at $-20{ }^{\circ} \mathrm{C}$ and allowed to warm up to ambient temperature. After quenching with water $(5.0 \mathrm{~mL})$ the reaction mixture was extracted with DCM $(2 \times 20 \mathrm{~mL})$. The organic phase was washed with diluted $\mathrm{HCl}(2 \times 10 \mathrm{~mL})$ and saturated $\mathrm{NaHCO}_{3}$ solution and dried over $\mathrm{Na}_{2} \mathrm{SO}_{4}$. The product was purified by Flash chromatography using DCM/MeOH gradient giving colorless oil (272 mg, $0.886 \mathrm{mmol}, 89 \%$ yield). ${ }^{1} \mathrm{H}$ NMR $\left(300 \mathrm{MHz}, \mathrm{CDCl}_{3}\right) \delta 6.11(\mathrm{t}, J=5.3 \mathrm{~Hz}, 1 \mathrm{H}), 5.61(\mathrm{~s}, 2 \mathrm{H}), 4.01(\mathrm{~d}, J=5.3 \mathrm{~Hz}, 2 \mathrm{H}), 3.90$ (t, $J=6.8 \mathrm{~Hz}, 2 \mathrm{H}), 2.61(\mathrm{t}, J=6.4 \mathrm{~Hz}, 2 \mathrm{H}), 2.49(\mathrm{t}, J=6.4 \mathrm{~Hz}, 2 \mathrm{H}), 1.45(\mathrm{q}, J=6.9 \mathrm{~Hz}, 2 \mathrm{H}), 1.21-1.07(\mathrm{~m}, 6 \mathrm{H}), 0.83-$ $0.66(\mathrm{~m}, 3 \mathrm{H}) .{ }^{13} \mathrm{C}$ NMR $\left(75 \mathrm{MHz}, \mathrm{CD}_{3} \mathrm{OD}\right) \delta 203.96,172.67,153.9,70.81,65.11,50.49,34.43,31.49,28.59,27.89,25.62$, 22.60, 14.07. LRMS, ESI: m/z $308.4[\mathrm{M}+\mathrm{H}]^{+}, 330.1[\mathrm{M}+\mathrm{Na}]^{+}$. HRMS: $\mathrm{m} / \mathrm{z}$ calculated for $\mathrm{C} 13 \mathrm{H} 22 \mathrm{ClNO} 330.1079$ $[\mathrm{M}+\mathrm{Na}]^{+}$, observed 330.1078 .

\subsubsection{Silver dibenzyl phosphate $\mathbf{3}$}

Dibenzyl phosphate silver salt was synthesized according to the published procedure [32]. Briefly, dibenzyl phosphate (1.00 $\mathrm{g}, 3.59 \mathrm{mmol})$ was dissolved in ethanol/water mixture $(50 / 50 \mathrm{~V} / \mathrm{V}, 10 \mathrm{~mL})$. The solution of sodium hydroxide $(3.59 \mathrm{~mL}, 1.00$ M, $3.59 \mathrm{mmol})$ was added and the solution stirred for $5 \mathrm{~min}$. Then silver nitrate $(610 \mathrm{mg}, 3.59 \mathrm{mmol})$ dissolved in hot water $(5.0 \mathrm{~mL})$ was added. A colorless precipitate was formed immediately. After $15 \mathrm{~min}$ the suspension was suction filtered and the precipitate washed with cold water $(5.0 \mathrm{~mL})$ and ethanol $(5.0 \mathrm{~mL})$ and dried in vacuo to yield colorless solid $(1.15 \mathrm{~g}, 3.00$ mmol, $83 \%$ yield). ${ }^{1} \mathrm{H}$ NMR (300 MHz, DMSO- $\left.d 6\right) \delta 7.32-7.20(\mathrm{~m}, 10 \mathrm{H}), 4.74(\mathrm{~s}, 2 \mathrm{H}), 4.72(\mathrm{~s}, 2 \mathrm{H}) .{ }^{13} \mathrm{C} \mathrm{NMR}(75 \mathrm{MHz}$, DMSO-d6) $\delta 140.07,139.96,128.73,127.75,66.88,66.80$. LRMS, ESI: m/z 277.0 [M-H]', 555.3 [2M-H]', $833.7[3 \mathrm{M}-\mathrm{H}]^{-}$.

\subsubsection{Hexyl 5-(((((bis(benzyloxy)phosphoryl)oxy)methoxy) carbonyl)amino)-4-oxopentanoate 4}

Procedure A: 2 ( $440 \mathrm{mg}, 0.60 \mathrm{mmol}$ ) was added to a suspension of sodium iodide (440 mg, $2.93 \mathrm{mmol}$ ) in acetone (20.0 mL) and refluxed at $60^{\circ} \mathrm{C}$ for $2 \mathrm{~h}$. The solvent was evaporated under reduced pressure and water $(10 \mathrm{~mL})$ added. The product was extracted with ether $(3 \times 20 \mathrm{~mL})$ and dried over $\mathrm{Na}_{2} \mathrm{SO}_{4}$. After the solvent was evaporated colorless oil was obtained and used immediately in the next step without purification. ${ }^{1} \mathrm{H}$ NMR $\left(300 \mathrm{MHz}, \mathrm{CDCl}_{3}\right) \delta 5.94(\mathrm{~s}, 2 \mathrm{H}), 5.70(\mathrm{t}, J=4.6 \mathrm{~Hz}, 1 \mathrm{H}), 4.01$ $(\mathrm{d}, J=5.3 \mathrm{~Hz}, 2 \mathrm{H}), 3.90(\mathrm{t}, J=6.8 \mathrm{~Hz}, 2 \mathrm{H}), 2.71(\mathrm{t}, J=6.4 \mathrm{~Hz}, 2 \mathrm{H}), 2.63(\mathrm{t}, J=6.4 \mathrm{~Hz}, 2 \mathrm{H}), 1.65-1.53(\mathrm{~m}, 2 \mathrm{H}), 1.35-$ $1.22(\mathrm{~m}, 6 \mathrm{H}), 0.88-0.84(\mathrm{~m}, 3 \mathrm{H})$. LRMS, ESI: m/z $400.6[\mathrm{M}+\mathrm{H}]^{+}, 417.1\left[\mathrm{M}+\mathrm{NH}_{4}\right]^{+}, 422.1[\mathrm{M}+\mathrm{Na}]^{+}$.

Crude hexyl 5-(((iodomethoxy)carbonyl)amino)-4-oxo-pentanoate was dissolved in toluene $(50.0 \mathrm{~mL})$ followed by the addition of silver dibenzyl phosphate $(346 \mathrm{mg}, 0.90 \mathrm{mmol})$. The suspension was heated at $50{ }^{\circ} \mathrm{C}$ for $1 \mathrm{~h}$ in the dark when the starting material was consumed. The brown precipitate was filtered off and the solvent evaporated under reduced pressure. The crude product was purified by Flash chromatography using DCM/MeOH gradient yielding colorless oil (139 mg, 0.25 mmol, $42 \%$ yield, 2 steps).

Procedure B: 2 (813 $\mathrm{mg}, 2.65 \mathrm{mmol})$ and silver dibenzyl phosphate $3(1.22 \mathrm{~g}, 3.18 \mathrm{mmol})$ were suspended in dry toluene $(50.0 \mathrm{~mL})$ and heated at $60^{\circ} \mathrm{C}$. After $5 \mathrm{~h}$ the dark brown suspension was suction filtered. The solvent was evaporated under reduced pressure and the crude product purified by Flash chromatography using a DCM/MeOH gradient yielding a colorless oil $\left(1.04 \mathrm{~g}, 1.90 \mathrm{mmol}, 72 \%\right.$ yield). The spectral properties of the product were identical using both procedures. ${ }^{1} \mathrm{H}$ NMR $\left(300 \mathrm{MHz}, \mathrm{CDCl}_{3}\right) \delta 7.33(\mathrm{~s}, 10 \mathrm{H}), 5.60(\mathrm{~d}, J=13.8 \mathrm{~Hz}, 2 \mathrm{H}), 5.06(\mathrm{~d}, J=7.9 \mathrm{~Hz}, 4 \mathrm{H}), 4.16-3.98(\mathrm{~m}, 4 \mathrm{H}), 2.82-2.50(\mathrm{~m}$, $4 \mathrm{H}), 1.67-1.51(\mathrm{~m}, 2 \mathrm{H}), 1.40-1.21(\mathrm{~m}, 6 \mathrm{H}), 0.88(\mathrm{t}, J=5.9 \mathrm{~Hz}, 3 \mathrm{H}) .{ }^{13} \mathrm{C}$ NMR $\left(75 \mathrm{MHz}, \mathrm{CDCl}_{3}\right) \delta 203.23,172.60$, $154.07,135.70,128.77,128.13,83.86,83.79,77.67,77.25,76.82,69.80,69.73,65.33,50.60,34.57,31.61,29.91,28.72$, 28.02, 25.74, 22.73, 14.21. LRMS, ESI: $\mathrm{m} / \mathrm{z} 550.3[\mathrm{M}+\mathrm{H}]^{+}, 567.3\left[\mathrm{M}+\mathrm{NH}_{4}\right]^{+}, 572.5[\mathrm{M}+\mathrm{Na}]^{+}$. HRMS: $\mathrm{m} / \mathrm{z}$ calculated for C27H36NO9P 550.2201 [M+H] $]^{+}$, observed 550.2205. 
2.3.5. Triethylammonium salt of hexyl 4-oxo-5-((((phosphonooxy)methoxy)carbonyl)amino)pentanoate 5

$4(600 \mathrm{mg}, 1.09 \mathrm{mmol})$ and triethylamine $(455 \mu \mathrm{L}, 3.30 \mathrm{mmol})$ were dissolved in absolute ethanol $(50.0 \mathrm{~mL})$. The reaction flask was flushed with argon before palladium on charcoal $(50 \mathrm{mg})$ was added. Argon was exchanged with hydrogen and the reaction mixture stirred under hydrogen at $1 \mathrm{bar}$ for $3 \mathrm{~h}$. The catalyst was filtered off and washed with absolute ethanol $(2 \times 10$ $\mathrm{mL})$. The product as colorless oil was obtained after evaporation of the solvent and extensive drying of the product in vacuo (506 mg, $3.05 \mathrm{mmol}, 99.0 \%$ yield). ${ }^{1} \mathrm{H}$ NMR $\left(300 \mathrm{MHz}, \mathrm{CD}_{3} \mathrm{OD}\right) \delta 5.49(\mathrm{~d}, J=12.6 \mathrm{~Hz}, 2 \mathrm{H}), 4.17-3.96(\mathrm{~m}, 4 \mathrm{H}), 3.17(\mathrm{q}, J$ $=7.3 \mathrm{~Hz}, 6 \mathrm{H}), 2.75(\mathrm{t}, J=6.3 \mathrm{~Hz}, 2 \mathrm{H}), 2.57(\mathrm{t}, J=6.3 \mathrm{~Hz}, 2 \mathrm{H}), 1.61-1.58(\mathrm{~m}, 2 \mathrm{H}), 1.45-1.17(\mathrm{~m}, 15 \mathrm{H}), 0.99-0.81(\mathrm{~m}$, $3 \mathrm{H}) .{ }^{13} \mathrm{C}$ NMR $\left(75 \mathrm{MHz}, \mathrm{CD}_{3} \mathrm{OD}\right) \delta 205.49,173.20,156.52,83.39,83.33,64.66,49.73,48.69,48.41,48.12,47.84,47.56$, 47.27, 46.99, 46.28, 33.82, 31.43, 28.49, 27.48, 25.51, 22.44, 13.20, 7.93. LRMS, ESI: m/z 368.0 [M-H]', 737.3 [2M-H]', 1106.7 [3M-H]'. HRMS: m/z calculated for C13H23NO9P 368.1116 [M-H]', observed 368.1115.

\subsubsection{Triethylammonium salt of hexyl 5-((hydroxy(phenoxy)phosphoryl)amino)-4-oxopentanoate 6}

Phenyl dichlorophosphate (407 mg, $1.93 \mathrm{mmol})$ was dissolved in dry THF $(20.0 \mathrm{~mL})$ and cooled to $0{ }^{\circ} \mathrm{C}$ on ice. Hexyl 5 amino-4-oxopentanoate $(491 \mathrm{mg}, 1.95 \mathrm{mmol}$ ) was added to the cooled solution followed by dropwise addition of dry triethylamine $(600 \mu \mathrm{L}, 4.31 \mathrm{mmol})$. The resulting suspension was stirred at $0{ }^{\circ} \mathrm{C}$ for $1 \mathrm{~h}$ and then allowed to warm-up to ambient temperature. After $2 \mathrm{~h}$ at ambient temperature the reaction mixture was filtered and the supernatant quenched with water $(5.0 \mathrm{~mL})$ and triethylamine $(650 \mu \mathrm{L}, 4.71 \mathrm{mmol})$. After $4 \mathrm{~h}$ at ambient temperature water $(20 \mathrm{~mL})$ and ethylacetate $(40$ $\mathrm{mL})$ were added. The organic phase was discarded and the aqueous phase re-extracted with DCM $(2 \times 20 \mathrm{~mL})$, washed with brine and dried with sodium sulfate. The crude product was purified by Flash chromatography using DCM/MeOH $(+0.1 \%$ TEA) gradient giving colorless oil $\left(542 \mathrm{mg}, 1.15 \mathrm{mmol}, 58 \%\right.$ yield). ${ }^{1} \mathrm{H}$ NMR $\left(300 \mathrm{MHz}, \mathrm{CD}_{3} \mathrm{OD}\right) \delta 7.34-7.14(\mathrm{~m}, 4 \mathrm{H})$, $7.11-6.96(\mathrm{~m}, 1 \mathrm{H}), 4.02(\mathrm{t}, \mathrm{J}=6.6 \mathrm{~Hz}, 2 \mathrm{H}), 3.82(\mathrm{~d}, \mathrm{~J}=8.3 \mathrm{~Hz}, 2 \mathrm{H}), 3.18(\mathrm{q}, \mathrm{J}=7.3 \mathrm{H}, 6 \mathrm{H}), 2.73(\mathrm{dd}, \mathrm{J}=7.2,5.6 \mathrm{~Hz}, 2 \mathrm{H})$, $2.53(\mathrm{dd}, \mathrm{J}=7.2,5.5 \mathrm{~Hz}, 2 \mathrm{H}), 1.67-1.48(\mathrm{~m}, 2 \mathrm{H}), 1.31(\mathrm{~m}, 17 \mathrm{H}), 0.96-0.84(\mathrm{~m}, 3 \mathrm{H}) .{ }^{13} \mathrm{C} \mathrm{NMR}\left(75 \mathrm{MHz}, \mathrm{CD}_{3} \mathrm{OD}\right) \delta$ 208.05 (d), 173.34, 153.34 (d), 129.12, 123.01, 120.66, 120.60, 64.66, 51.41, 48.77, 46.58, 33.94, 31.44, 28.51, 27.64, 25.52, 22.46, 13.30, 8.12. LRMS, ESI: m/z 370.4 [M-H]-, 741.5 [2M-H]-, $1112.7[3 \mathrm{M}-\mathrm{H}]-, 372.4[\mathrm{M}+\mathrm{H}]^{+}, 743.7[2 \mathrm{M}+\mathrm{H}]^{+}, 1114.8$ $[3 \mathrm{M}+\mathrm{H}]^{+}$. HRMS: $\mathrm{m} / \mathrm{z}$ calculated for C17H26NO6P $372.1571[\mathrm{M}+\mathrm{H}]^{+}$, observed 372.1573.

\subsection{Chemical stability}

The stability was assessed at $\mathrm{pH} 4.00$ (acetate buffer), 7.40 (phosphate buffer) and 8.90 (borate buffer). The concentration of all buffers was $25 \mathrm{mM}$. The compound of interest was dissolved in buffer solution at $5 \mathrm{mM}$ concentration and $\mathrm{pH}$ adjusted if necessary. The vial was placed in a temperature-controlled LC-MS autosampler preheated at $37{ }^{\circ} \mathrm{C}$ and injected at regular time points. The chromatograms were integrated and AUC of the compounds was determined and plotted as a function of time.

\subsection{Alkaline phosphatase assay}

The compounds $(5.0 \mathrm{mM})$ were dissolved in borate buffer $(25 \mathrm{mM})$ at $\mathrm{pH} 8.90$ containing $\mathrm{MgCl} 2(0.5 \mathrm{mM})$. Alkaline phosphatase from calf intestine (Applichem-Axon Lab) dissolved in the same buffer was added and the vial was placed in a temperature-controlled LC-MS auto-sampler preheated at $37{ }^{\circ} \mathrm{C}$ and injected at regular time points. The chromatograms were integrated and AUC of the starting material was determined and plotted as a function of time.

\subsection{Cell culture}

Human glioblastoma cells U87Mg (ATTC ${ }^{\circledR}$ HTB-14 ${ }^{\mathrm{TM}}$ ) were grown in monolayers and maintained in Minimum Essential Media (31095-029, Thermo Fisher Scientific) supplemented with $10 \%$ fetal calf serum (CVFSVF00-01, Eurobio), 100 $\mu \mathrm{L} / \mathrm{mL}$ streptomycin and $100 \mathrm{IU} / \mathrm{mL}$ penicillin (15140-122, Thermo Fisher Scientific). Cells were cultivated at $37{ }^{\circ} \mathrm{C}$ in humidified $95 \%$ air and $5 \% \mathrm{CO}_{2}$ atmosphere and routinely maintained by serial passage in a new medium every 5 days.

\subsection{PpIX fluorescence time profiles}

U87Mg cells $(10,000$ cells/well) were seeded in a 96-well plate (clear bottom black plate, 3603, Corning). The following day the medium in the wells was replaced with medium containing increasing concentrations $(0.033,0.1,0.33,1,2$ and 3.3 $\mathrm{mM}$ ) of compounds of interest. 5-ALA-Hex was used as positive control. PpIX fluorescence was recorded with a plate reader (Safire, Tecan) at different time points $(1,2,4,6,8$ and $24 \mathrm{~h}$ ). Excitation wavelength was set at $405 \mathrm{~nm}$ and emission wavelength at $635 \mathrm{~nm}$. Cells were maintained at $37^{\circ} \mathrm{C}$ for the duration of the assay. 


\subsection{Preparation and treatment of U87Mg tumor spheroids}

HEMA coated plates were prepared by dissolving Poly-HEMA in ethanol. In a laminar flow box, $50 \mu \mathrm{L}$ was dispensed in each well of a round-bottom 96-well plate. The 96-well plates were left under the laminar flow box to evaporate the solvent. After $24 \mathrm{~h}$ they were covered with lids, protected by aluminum foil and kept at room temperature until the experiments. For spheroid preparation, $200 \mu \mathrm{L} /$ well of U87Mg cell suspension at the density of $0.5 \times 10^{4}$ cells $/ \mathrm{mL}$ was dispensed into coated 96-well plates using a multichannel pipette. In order to obtain optimal three-dimensional structures 3\% of Basement Membrane Matrigel® Matrix (356234, Corning) was added into the cell suspension prior to seeding. Plates were incubated at $37{ }^{\circ} \mathrm{C}$ in a humidified $95 \%$ air and $5 \% \mathrm{CO}_{2}$ atmosphere.

\subsection{Confocal laser-scanning microscopy of spheroids}

On day 2 of spheroid tumor development the spheroids were treated with $0.33 \mathrm{mM}$ concentration of compounds of interest and 5-ALA-Hex as positive control. Non-treated spheroids incubated with cell medium were used as a negative control. Spheroids were kept at $37{ }^{\circ} \mathrm{C}$ in humidified $95 \%$ air and $5 \% \mathrm{CO}_{2}$ atmosphere for $4 \mathrm{~h}$ after which they were washed with cell medium. The non-fixed U87Mg spheroids were incubated for $1 \mathrm{~h}$ with Hoechest 33342 stain (62249, Thermo Fisher Scientific) to achieve the staining of nuclei. Prior to imaging, spheroids were transferred to a glass bottom microwell dishes (35 mm petri dish, $14 \mathrm{~mm}$ Microwell, MatTek Corporation). Detection and localization of PpIX fluorescence in intact spheroids was done with the Zeiss LSM 780 inverted confocal microscope. The Z-stack images were taken with a 405 nm laser using 415 - $493 \mathrm{~nm}$ and 615 - $659 \mathrm{~nm}$ filters, pinholes of $27 \mu \mathrm{m}$, and a 10x objective. During the image acquisition time, spheroids were kept at $37{ }^{\circ} \mathrm{C}$ in a humidified chamber (INUBTF-WSKM-F1, Tokai Hit). Obtained z-stack fluorescence images were analyzed using Zeiss ZEN lite software to produce the maximal intensity projection image for each sample.

\subsection{Chicken chorioallantoic membrane (CAM) spheroid model}

\subsubsection{Egg incubation}

Fertilized chicken eggs (University animal facility, University of Geneva, Geneva, Switzerland) were placed in the incubator (MG 200, Savimat, chauffry, France) and incubated at $37{ }^{\circ} \mathrm{C}$ and $65 \%$ relative humidity. The eggs were placed with the narrow apex oriented downwards. During the first three days, eggs were rotated gently using the automatic rotation mode of the incubator. On embryonic development day 3 (EDD3) a small hole $(\approx 3 \mathrm{~mm})$ was made at the narrow apex of the eggshell and closed with an adhesive tape. Eggs were returned to the incubator and placed so that the narrow apex was directed upward. Rotation was no longer necessary after this point until the end of the experiments.

\subsubsection{Nodule inoculation into CAM}

U87Mg spheroids were prepared as described above using $2.5 \times 10^{4}$ cells $/ \mathrm{mL}$. Spheroids grew 4 days before inoculation into the CAM. On EDD7, the hole in the eggshell was enlarged to allow access to the CAM vasculature, using a needle (25 Gauge) a hole was drilled in the CAM. A binocular lens Leica M80 (Wetzlar, Germany) was used to perform the inoculation. Once the hole was pierced in the CAM, the spheroid was placed in the cavity beneath the hole. Cell medium $(20 \mu \mathrm{L})$ was placed on the spheroid to allow the tumor to attach to the CAM membrane and develop. Then, the eggs were sealed with parafilm and returned to the incubator to let spheroids grow until EDD13.

\subsection{Fluorescence imaging of CAM tumors.}

On EDD13, the compounds were injected intravenously into the CAM vasculature. The hole enlarged on EDD7 was further widened if necessary to allow more access to vessels and to facilitate handling. Injection (10-40 $\mu \mathrm{L})$ was performed preferentially into a large blood vessels using a needle (gauge 33, $51 \mathrm{~mm}$, tap $\mathrm{N}$ type) attached to a $100 \mu \mathrm{L}$ syringe (Hamilton, Reno, NV). Fluorescence imaging of tumor nodules was done with 12-bit monochrome CDD camera (Retiga EX Q-Imaging Canada) connected to fluorescence Eclipse E600 FN microscope with a CFI achromat objective characterized by magnification $4 \times$, numerical aperture of 0.10 and a working distance of $30 \mathrm{~mm}$ (Nikon, Tokyo, Japon). A conical holder was used to place the eggs during experimentation under the objective of fluorescence microscope. A mercury arc lampHBO 103/W/2 (MS Scientific Berlin, Germany) was used to provide illumination. For the detection of PpIX a BV-2A cube (Nikon, Tokkyo, Japan) with an excitation filter: $400-440 \mathrm{~nm}$, a dichroic mirror (455 nm) and an emission filter (470 nm) was used. A hollow slider filter $650 / 50 \mathrm{~nm}$ was added. Band pass filter 560/40 was used to image the autofluorescence of tumors. All pictures were taken with a $90 \mathrm{~ms}$ exposure and gain set at 50. Tumor imaging was performed at time 0 , 30 , 60 and $120 \mathrm{~min}$ after injection. Autofluorescence images were taken before injection. Images were processed using Openlab software version 3.1.5. Image resolution was $678 \times 518$ pixels with a binning set at 2 and the brightness and contrast for all images. Data was analysed using multiple t-tests and statistical significance determined at each time point. 


\subsection{Chick embryo acute toxicity}

The experiments were performed according to published procedures and standard animal treatment practices. Escalating doses of compounds dissolved in milliQ water and $\mathrm{pH}$ adjusted to 7.4 were administrated to embryos via intravenous injection. The viability of chick embryos has been evaluated after $24 \mathrm{~h}$ after injection.

\subsection{Statistical Analysis}

GraphPad Prism 6.0.1 for Windows (GraphPad Software, version 6.05, San Diego, CA, USA) was used for biological data analysis and treatment. All results are presented as means \pm standard deviations. Where applicable one-way ANOVA or multiple t-tests was used to analyse the results. $P$ values $<0.05$ were considered as statistically significant.

\section{Results and discussion}

5-ALA is currently marketed for several applications. In cancer detection and management its use is sparse with the notable exception of FGR for glioblastoma. 5-ALA-Hex is a hexyl ester derivative of 5-ALA induces saturation of fluorescence induction in tumor cell lines several-fold higher compared to 5-ALA in vitro. Its superiority in fluorescence induction at lower doses and shorter time resulted in its approval for topical application in FGR of bladder cancer. However, the toxicity profile of 5-ALA-Hex narrows its therapeutic index meaning it cannot be administered safely into systemic circulation. Furthermore, 5-ALA and its hexyl ester suffer from inherent instability coming from the free amino group that results in the irreversible dimerization rendering it inactive (Figure 2). To our knowledge, no 5-ALA derivative modified at the amino group showed robust fluorescence profile in vitro or in vivo [33]. The reason for the biological inactivity of the aminomodified derivatives is the high substrate specificity of porphobilinogen synthase coming from its reaction mechanism through the formation of Schiff base linkage between free amino group of 5-ALA and the lysine residues in the enzyme's active site [34].

We set out to investigate whether it would be possible to solve this 5-ALA paradox, meaning the modification of the 5-amino end of the molecule that will render the molecule stable and impede the dimerization degradation but not at the expense of biological activity. To this end the protecting group attached to the 5-amino group needs to be very efficiently cleaved off either chemically or enzymatically in vitro and in vivo. We present 2 new classes of amino modified 5-ALA prodrugs that both tackle this problem (Figure 3). The first class contains 5-ALA and a phosphate group connected via a short chemical linker that is designed to yield 5-ALA or its ester upon the action of alkaline phosphatase. After the enzymatic cleavage the subsequent hydrolysis of the self-immolative linker[35] is spontaneous. We therefore named this class phospho-selfimmolative 5-ALA (PSI-ALA).

The second class, called phospho-5-ALA (P-ALA), is also activated by alkaline phosphatase but gives 5-ALA directly after enzymatic action without the use of a self-immolative spacer. Both classes were designed to display improved stability since the amino group is protected and at the same time reduce the acute toxicity of 5-ALA-Hex which can at least partially be explained by the free positively charged amino group. The differences in amine-protecting groups were also expected to give different sensitivity towards the target enzyme. We decided to synthesize the hexyl esters of both new classes because the 5ALA-Hex demonstrates vastly superior profile in fluorescence induction as compared to 5-ALA. The two classes are hence represented by hexyl ester derivatives compound 5 (PSI-ALA-Hex) and compound 6 (P-ALA-Hex) and compared to ALAHex. It did not escape our notice that the concept of 5-ALA derivatives that can be activated by ubiquitously expressed hydrolases can also be extended to other enzymes such as glycosidases, nucleases, oxyreductases, and ureases. 


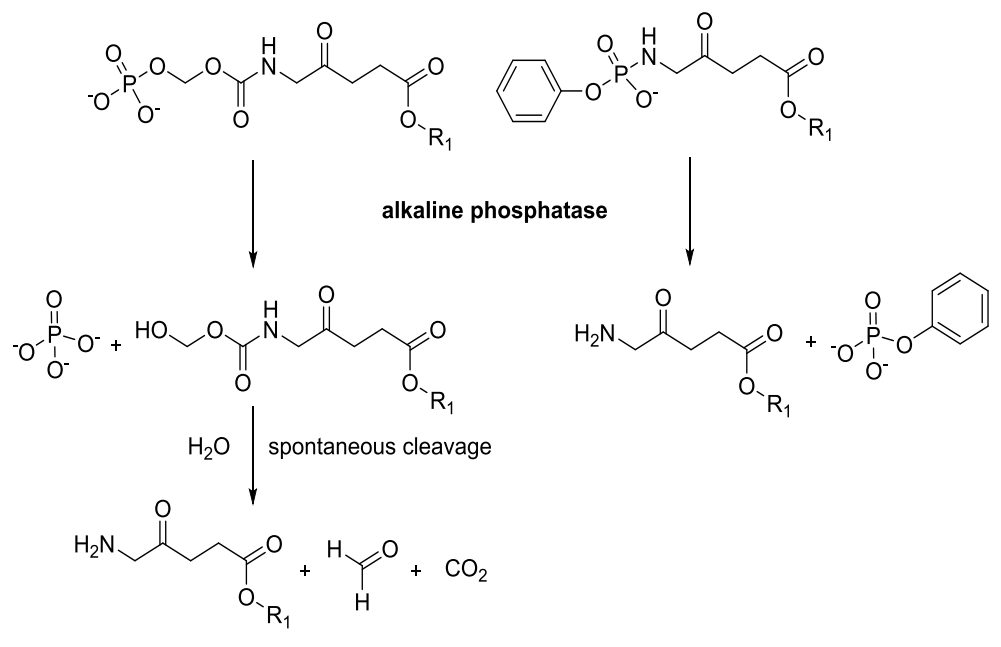

Fig. 3. Bioactivation mechanism of phosphatase-sensitive prodrugs of ALA. Alkaline phosphatase enzymatic cleavage of phosphate group is followed by spontaneous conversion of ALA-hemiacetal into ALA (PSI-ALA, left) or affords ALA ester directly (P-ALA, right).

\subsection{Synthesis}

The synthesis of PSI-ALA class of compounds was done in four or five synthethic steps depicted in Figure 4. 5-ALA was used as starting material and was firstly esterified by 1-hexanol to give $\mathbf{2}$ in excellent yield. The self-cleavable linker between the phosphate group and 5-ALA moiety was introduced with chloromethyl chlorformate and triethylamine as base at $-20{ }^{\circ} \mathrm{C}$ to keep the dimerization side reaction to a minimum. 3 was obtained in very good yield. The introduction of the phosphate group was attempted in two steps. The Finkelstein reaction using an excess of sodium iodide in refluxing acetone gave firstly more electrophilic iodide derivative. It was used in the following step without purification as it proved to be poorly stable and degrading even stored at $-30{ }^{\circ} \mathrm{C}$ under argon. The following step gave the protected phosphate derivative 5 by reacting $\mathbf{4}$ with silver salt of dibenzyl phosphate at room temperature in moderate yield for the 2 steps $(42 \%)$. The low yield was presumably due to the degradation of the poorly stable iodomethyloxycarbonyl derivative. We decided to attempt a direct conversion of $\mathbf{2}$ to protected phosphate $\mathbf{4}$ by reacting the same chloro derivative $\mathbf{2}$ with the dibenzyl phosphate silver salt $\mathbf{3}$ by refluxing in toluene at $60{ }^{\circ} \mathrm{C}$ which gave a much better $72 \%$ yield. Hydrogenolysis using $\mathrm{Pd} / \mathrm{C}$ as catalyst in absolute ethanol and excess of TEA gave the final product $\mathbf{6}$ in quantitative yield. It is noteworthy that the presence of base is essential for the outcome of the deprotection step. The self-immolative linker is acid-sensitive and is spontaneously cleaved under these reaction conditions in the absence of triethylamine as base. 

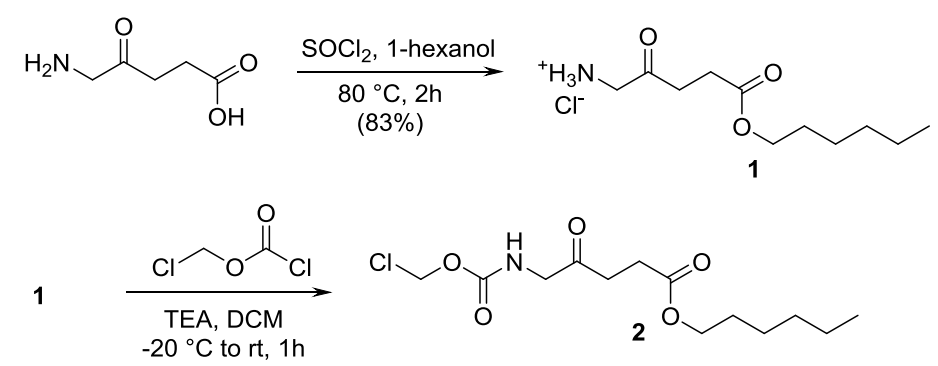

$(89 \%)$

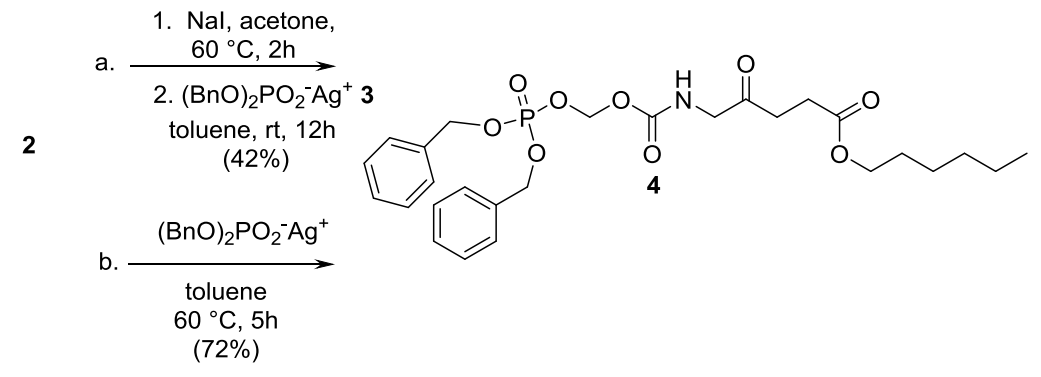

4
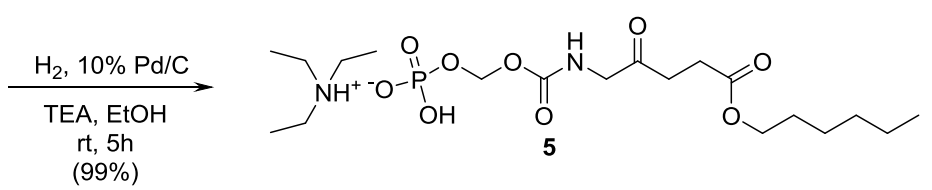

1
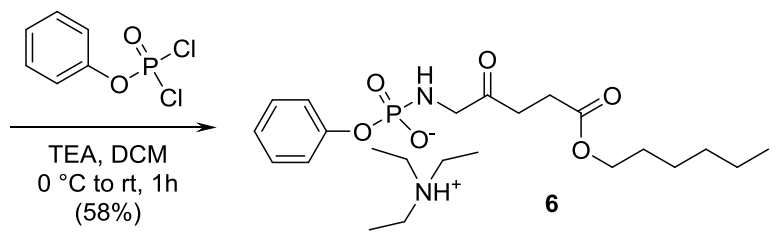

Fig.4. Synthesis of phosphatase-sensitive ALA prodrugs. PSI-ALA-Hex 5 contains a self-immolative linker whilst phospho-ALA-Hex 6 does not contain a chemical linker.

Contrary to the PSI-ALA-Hex, the P-ALA-Hex was synthesized in a straightforward 2-step conversion from 5-ALA. The esterification step yielding 2 was the same as described above for PSI-ALA-Hex. Reacting 2 with 1 eq of phenyl dichlorophosphate at $0{ }^{\circ} \mathrm{C}$ to increase the yield by reducing the dimerization rate of 5-ALA-Hex under basic conditions gave the final product $\mathbf{6}$ as TEA salt after extraction and chromatographic purification.

\subsection{Chemical stability}

Both classes were designed to improve the chemical stability profile of 5-ALA and 5-ALA-Hex. Figure 5 (top) shows that the stability profiles at $36{ }^{\circ} \mathrm{C}$ the $5 \mathrm{mM}$ solution of ALA-Hex in different buffers displays pH dependent stability curves. At $\mathrm{pH} 4$ the molecule is stable for prolonged periods of time because the amino group is fully protonated $\left(\mathrm{pKa}=8.9\right.$ at $25^{\circ} \mathrm{C}$ ). However, at $\mathrm{pH} 7.40$ a significant increase in deprotonation of the amino group facilitates fast and irreversible dimerization. The molecule is fully degraded under accelerated conditions at $37{ }^{\circ} \mathrm{C}$ in less than $60 \mathrm{~min}$. This phenomenon is even more pronounced at $\mathrm{pH}$ 8.9. Contrary, PSI-ALA-Hex 5 shows much improved stability. At neutral and basic $\mathrm{pH}$ there is hardly any degradation occurring in $6 \mathrm{~h}$ whilst at acidic $\mathrm{pH}$ values the molecule shows slow degradation which was expected since both carbamate and phosphate groups are known to be cleaved under acidic conditions. The P-ALA-Hex 6 shows showed excellent stability similar to PSI-ALA-Hex. At pH 4.00, 7.40 and 8.90 the molecule stays intact for hours compared to very fast degradation of ALA-Hex which occurs in minutes. The stability profiles are vastly superior to that of 5-ALA-Hex as is expected from the protection of the amino group. These observation are also in agreement with reports on the stability of 5 ALA itself [22, 36]. 

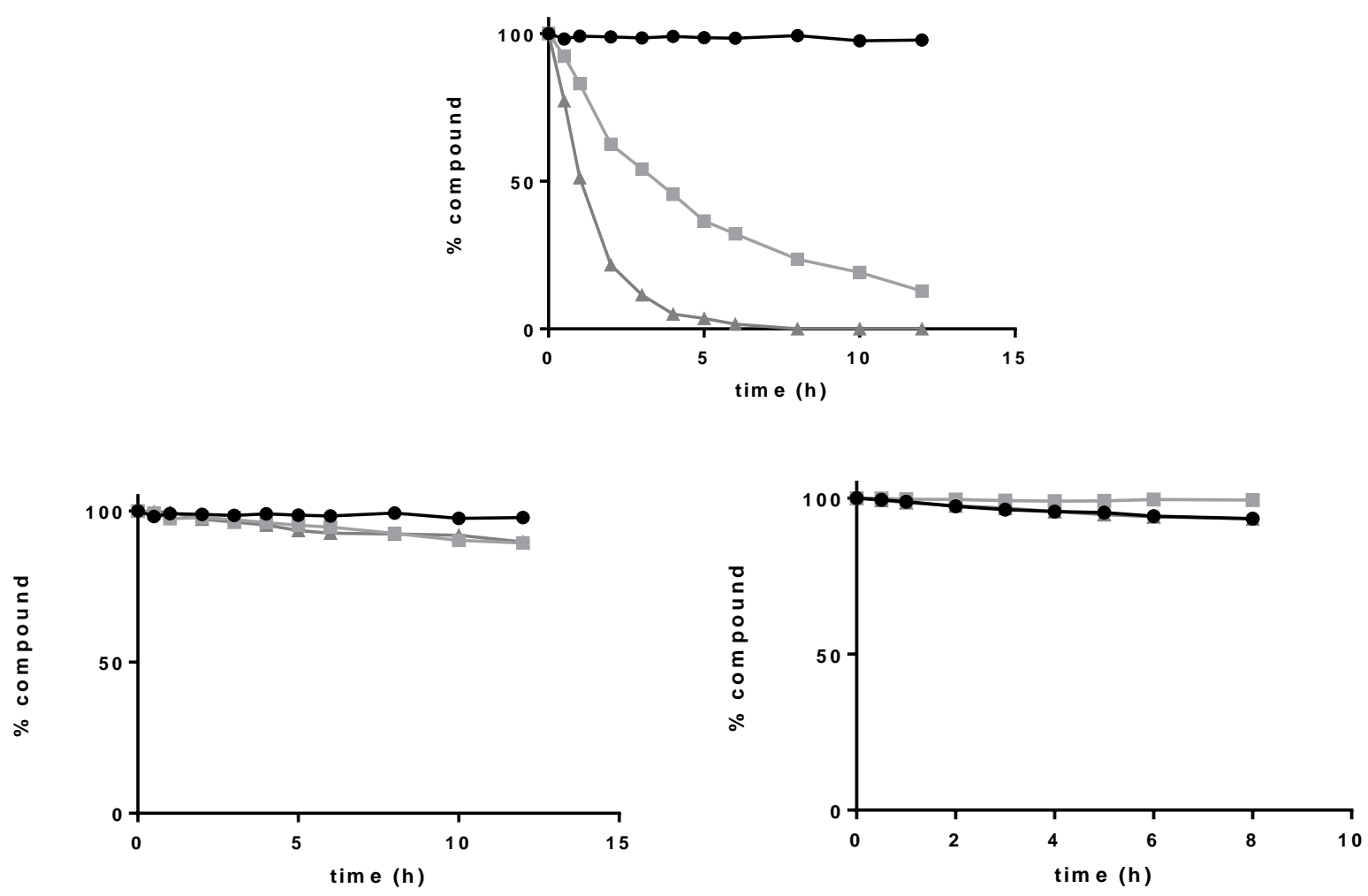

Fig. 5. Stability of 5-ALA-Hex (top), PSI-ALA-Hex, (bottom left), and P-ALA-Hex (bottom right) at $37{ }^{\circ} \mathrm{C}$ at different pH values: pH 4.0 (circles), 7.4 (squares), and 8.9 (triangles). Each time point represents the mean $\pm \mathrm{SD}(\mathrm{n}=3)$.

\subsection{Enzymatic activation}

The increased chemical stability displayed by both new ALA chemical classes is a consequence of the 5-amino group modification. However, the increase of stability might also cause a dramatic decrease in PpIX production as shown by amino-acid protected 5-ALA derivatives [25]. Therefore, we first tested 5-ALA-Hex release from PSI-ALA-Hex and PALA-Hex in the presence of alkaline phosphatase. PSI-ALA-Hex which contains the free phosphate group was found to be an excellent substrate for the target enzyme. $1 \mathrm{U}$ of alkaline phosphatase resulted in almost full activation and conversion to 5-ALA-Hex in 60 min (Figure 6, left). The conversion was not complete presumably because of the experimental conditions. PSI-ALA-Hex was enzymatically converted to 5-ALA-Hex which in turn formed dimerized dihexyl-2,5-( $\beta$-carboxyethyl) dihydropyrazine at $\mathrm{pH}$ 8.90. This product is water-insoluble and precipitates out of solution resulting in enzyme inhibition, causing the curve to flatten out after $80 \%$ conversion.

Without the presence of a self-immovable linker the conversion into 5-ALA Hex slowed substantially down. P-ALA-Hex, performed quite differently when subjected to enzymatic activation. The conversion was achieved much more slowly in the presence of $100 \mathrm{U}$ of alkaline phosphatase (Figure 6, right). It was actually surprising that P-ALA-Hex is a substrate for alkaline phosphatase at all but this can be explained by the broad substrate specificity of this class of enzymes [37]. This finding led to a 5-ALA prodrug class that is activated much more slowly. Therefore, fine-tuning the structure of phosphatasesensitive 5-ALA prodrugs, allows for the modulation of 5-ALA release. 

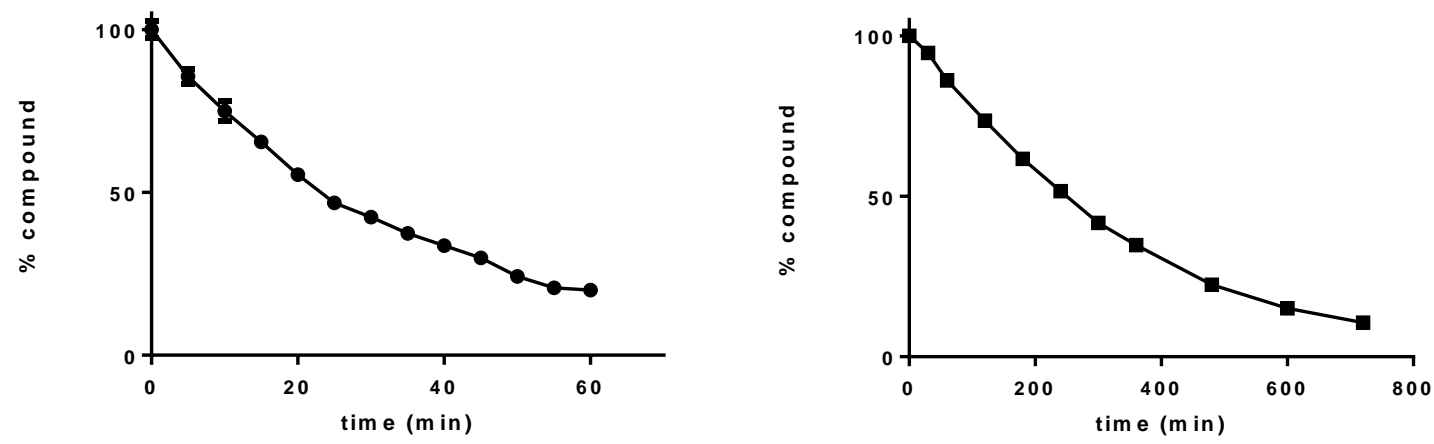

Fig. 6. Contolled activation of phosphatase-sensitive prodrugs in vitro. PSI-ALA-Hex in the presence of $1 \mathrm{U}$ alkaline phosphatase at $\mathrm{pH} 8.90$ of is cleaved very rapidly (right). P-ALA-Hex displays a much slower release profile in the presence of $100 \mathrm{U}$ of alkaline phosphatase (bottom). Each time point represents the mean $\pm \mathrm{SD}(\mathrm{n}=3)$.

\subsection{In vitro PpIX production}

We assayed the compounds of interest for in vitro production of PpIX in U87Mg glioblastoma cell line. This phenotypic assay measured the final fluorescence intensity of PpIX and not each individual step of the prodrug activation and conversion. The compounds were incubated with cells at different concentrations and compared to5-ALA-Hex. 5-ALA itself induces PpIX up to 100 - 200 times less efficiently than 5-ALA-Hex in certain cancer cell lines and was therefore not used as control in this assay [38, 39]. Figure 7 presents the PpIX fluorescence intensity time profile in U87Mg cells. It is evident that the PSI-ALA-Hex performs better than 5-ALA-Hex over $24 \mathrm{~h}$. The fact that the PSI-ALA-Hex curves at different concentrations are overlayed means that the PpIX production is saturated under our experimental conditions. To our surprise, the 5-ALA-Hex fluorescence intensity (green lines) is lower than that of PSI-ALA-Hex. It was reasoned that this is due to some dark toxicity or instability of 5-ALA-Hex at these concentrations.

Despite the lower rate of in vial activation P-ALA-Hex also performed well in this assay. At 0.33 mM fluorescence intensity increases linearly over the $24 \mathrm{~h}$ of the assay. Similarly to PSI-ALA-Hex, this molecule also gave higher fluorescence intensities than ALA-Hex at every time point, again hinting to lower toxicity and stability.

Generally speaking, the optimal concentrations of both prodrugs to induce valid fluorescence intensities were comparable to those required for 5-ALA-Hex with best results obtained in the range of 0.03-0.33 mM (see Supporting information). PALA-Hex, however, required higher concentrations used which corresponded well with the phosphatase activation profile which was significantly slower than that of PSI-ALA-Hex. It should be noted that we have also a larger variety of PSI-ALA and P-5-ALA esters (data not shown). However, we mainly focused on 5-ALA-Hex compounds since 5-ALA-Hex is clinically approved. However, it is noteworthy mentioning that the corresponding methyl esters did not show any clinically valid fluorescence intensities in vitro.

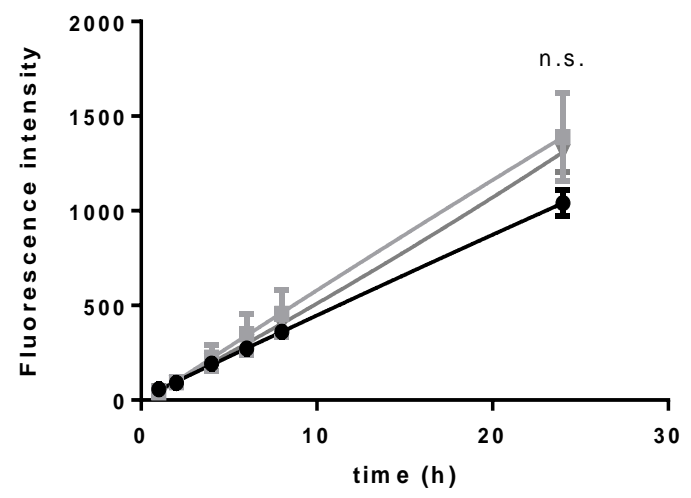

Fig. 7. In vitro PpIX fluorescence kinetics in U87Mg cells. 0.1 mM PSI-ALA-Hex (squares) and P-ALA-Hex (triangles) at optimal concentrations $0.1 \mathrm{mM}$ and $0.33 \mathrm{mM}$ respectively, outperform 5-ALA-Hex at $0.33 \mathrm{mM}$ (circles). n.s. p>0.05. 


\subsection{PpIX production in full U87Mg tumor spheroids.}

The phenotypic fluorescence assay in cell monolayers described above was used as medium-throughput screen for new 5ALA prodrugs. Despite its robustness, it has very limited ability to predict penetration across several layers of cells typically found in neoplasms. We therefore performed live U87Mg spheroid imaging to determine if the new prodrugs penetrate into the core of the 400-500 $\mu \mathrm{m}$ glioblastoma microspheroids (Figure 8). The fluorescence was visible throughout the entire spheroids (Supplementary information, z-stack) and was more pronounced than the fluorescence produced by 5-ALA-Hex administration. This was especially the case for the P-ALA-Hex, which is lipophilic and negatively charged. It is noteworthy that Hoechst 33342 stained only the cell nuclei of the surface cells proving evidence for the difficulty of passage through several layers of cells.

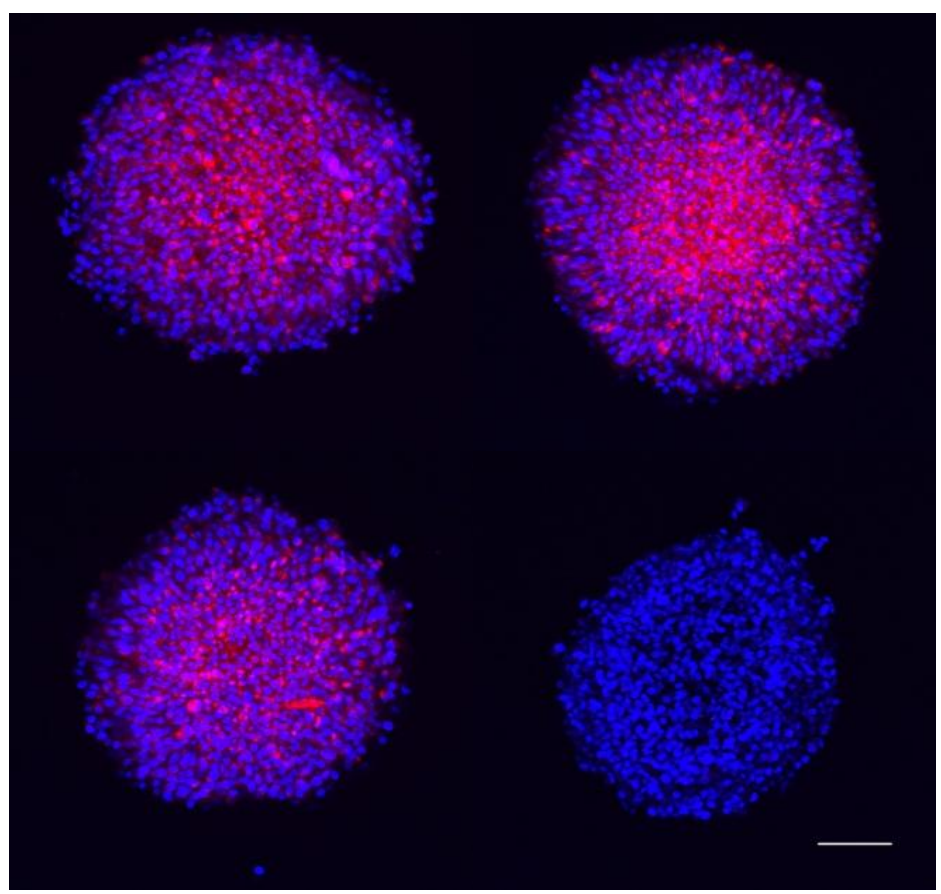

Fig. 8. Confocal fluorescence images of U87Mg tumor spheroids after incubation with PSI-ALA-Hex 5 (top left), P-ALAHex 6 (top right), 5-ALA-Hex as positive control (bottom left) and cell medium negative control (bottom right). PpIX fluorescence is represented in red and nuclei staining with Hoechest 33342 in blue. Scale bar $100 \mu \mathrm{m}$.

\subsection{In vivo chick acute toxicity.}

Encouraged by the robust in vitro fluorescence profiles we assessed the acute in vivo toxicity of our compounds in living chick embryos [40]. 5-ALA-Hex is known for its pronounced acute toxicity after intravenous injection and we determined the LD50 of $75 \mu \mathrm{mol} / \mathrm{kg}$. PSI-ALA-Hex was better tolerated and LD50 values of $200 \mu \mathrm{mol} / \mathrm{kg}$ were achieved. We postulated that these higher LD50 is a consequence of rapid conversion into 5-ALA-Hex. Therefore, the very high doses of P-ALA-Hex that were tolerated by chick embryos came as no surprise. Since this compound is much more slowly converted into 5-ALAHex (and 5-ALA) in all tissues expressing alkaline phosphatase, the LD50 was $500 \mu \mathrm{mol} / \mathrm{kg}$ which is 5-fold increase in tolerated doses compared to 5-ALA-Hex.

\subsection{In vivo CAM $\mathrm{U} 87 \mathrm{Mg}$ spheroid tumor model.}

Using the chorioallantoic membrane (CAM) model U87-Mg tumor spheroids were obtained using a modified procedure [41, 42]. Spheroids approximately of $200 \mu \mathrm{m}$ were implanted and microtumors could be observed on the CAM several days later. Compounds were injected and the fluorescence in micro tumors was imaged (Figure 7). In accordance with in vitro data, PSI-ALA-Hex started to outline the tumors as early as $30 \mathrm{~min}$ post injection followed by an excellent and statistically significant signal to background at $1 \mathrm{~h}$ and also at $2 \mathrm{~h}$ (Figure 9 and 10). As expected, P-ALA-Hex displayed delayed onset of the fluorescence signal but a robust contrast nevertheless. The fluorescence decreased to background levels in chick embryos in $5 \mathrm{~h}$ which is a clinically relevant advantage. The kinetics of the fluorescence signal were very important here as this gave an indication to prodrug activation, PpIX biosynthesis and final conversion to non-fluorescent heme or clearance out of the tumors (see Supplementary data). Interestingly, PpIX that was injected as one of the controls, to demonstrate that the PpIX 
was produced within the tumors and not in other developing tissues in the embryos, showed no preferential accumulation and fluorescence in the tumors (Figure 9).

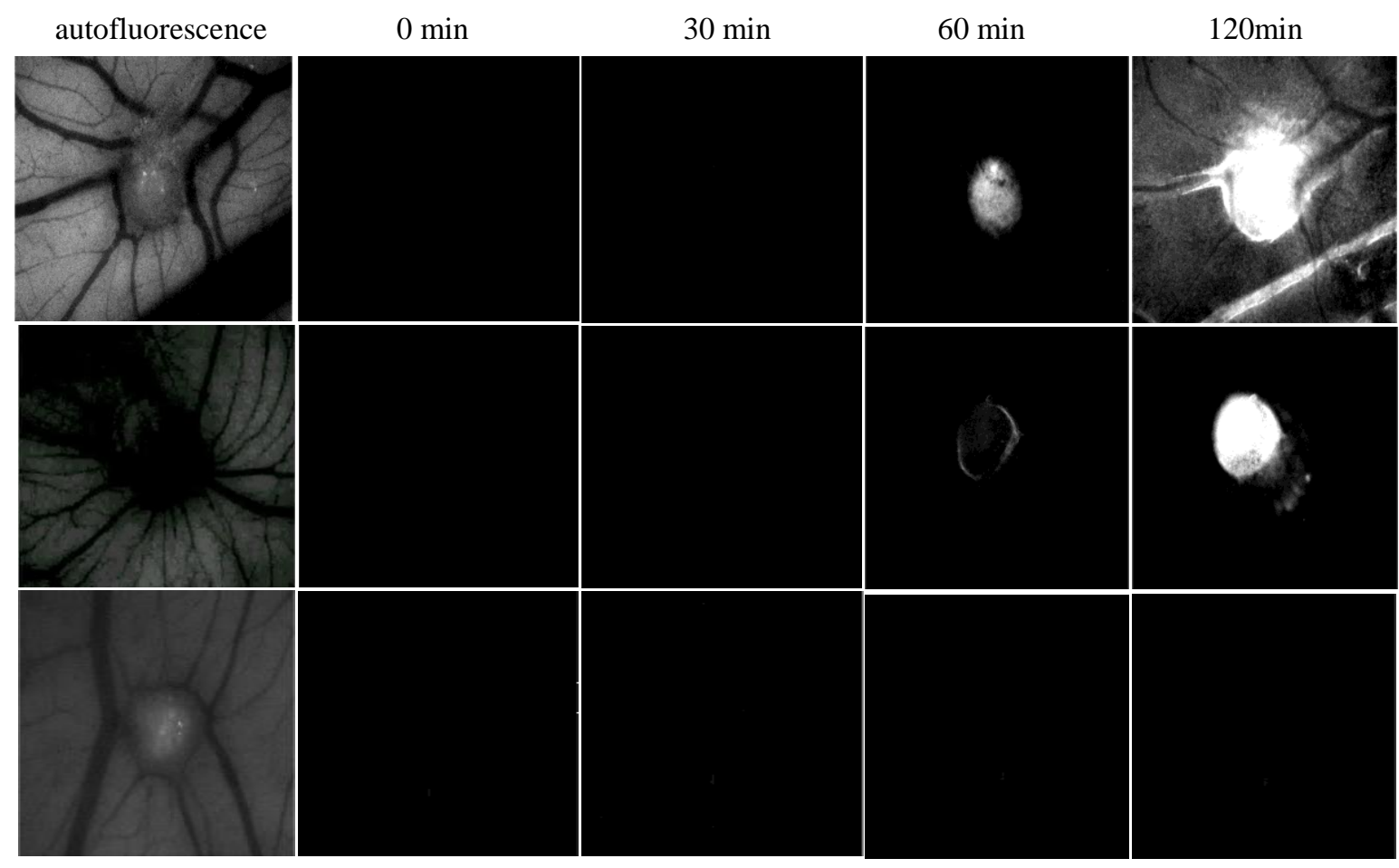

Fig. 9. In vivo fluorescence of CAM U87Mg spheroid tumor. Injection of non-fluorescent PSI-ALA-Hex (100 $\mu \mathrm{mol} / \mathrm{kg}$, top), P-ALA-Hex (300 $\mu \mathrm{mol} / \mathrm{kg}$, middle) and fluorescent PpIX (100 $\mu \mathrm{mol} / \mathrm{kg}$, bottom). Tumor auto-fluorescence images at time 0 (left) and fluorescence images at times 0,30,60 and 120 min.

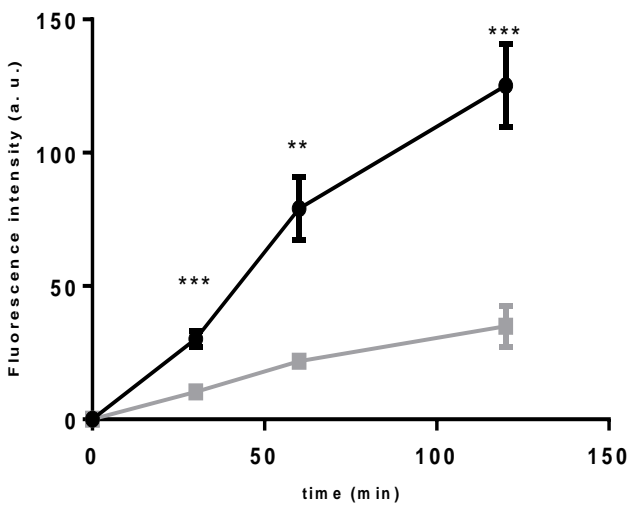

Fig. 10. In vivo CAM U87Mg spheroid tumor fluorescence time profiles kinetics (circles) as compared to the surrounding chorioallantoic membrane (squares). Injection of non-fluorescent PSI-ALA-Hex $(100 \mu \mathrm{mol} / \mathrm{kg})$ produces PPIX fluorescence; $\mathrm{n}=3, * * \mathrm{p}<0.01, * * * \mathrm{p}<0.001$. 


\section{Conclusions}

FPD and FGR remain perhaps the most promising upcoming modalities in tumor management and therapy. 5-ALA and 5ALA-Hex have been at the forefront of small molecules used for FGR. However their use is limited due to unfavorable stability, pharmacokinetics and toxicity profiles. We have presented 2 new 5-ALA prodrugs: PSI-ALA-Hex and P-ALA-Hex that exhibit clearly improved chemical stability at acidic, neutral and basic $\mathrm{pH}$ values. They also show designed and structure-dependant sensitivity to alkaline phosphatase. The robust production of PpIX and red fluorescence in U87Mg glioblastoma cancer cell lines is better than the state of the art fluorescence levels of ALA-Hex. Acute toxicity was reduced several fold for the PSI-ALA-Hex whilst P-ALA-Hex shows unprecedented 7-fold increase in LD50 in chick embryos. Clinically translational fluorescence profiles in CAM implanted U87Mg tumor spheroids were observed after the injection of both compounds. Statistically significant fluorescence was observed throughout the tumor mass within the clinically acceptable time-frame This work opens the doors towards new ALA prodrug based FGR with enormous translational potential for fluorescence-based detection of tumors. Furthermore, these proof-of-principle studies of stable 5-ALA derivatives open the way towards self-assembling nanomicelle-forming 5-ALA derivatives.

\section{Acknowledgements}

We thank the Mass spectrometry center of the University of Geneva for the high-resolution mass spectroscopy experiments. We would also like to acknowledge the support of the NMR facility of School of Pharmaceutical Sciences, and the Chemistry NMR facility at the University of Geneva, Switzerland. This work was supported, by grants from the Swiss National Science Foundation (310000-109402, CR32I3_129987, 205320_138309; 205321_126834, CR32I3_147018) and the Swiss Government Excellence Scholarships for Foreign Scholars.

\section{References}

[1] Q. Peng, T. Warloe, K. Berg, J. Moan, M. Kongshaug, K.E. Giercksky, J.M. Nesland, 5-aminolevulinic acid-based photodynamic therapy - Clinical research and future challenges, Cancer-Am Cancer Soc, 79 (1997) 2282-2308.

[2] N. Lange, P. Jichlinski, M. Zellweger, M. Forrer, A. Marti, L. Guillou, P. Kucera, G. Wagnieres, H. van den Bergh, Photodetection of early human bladder cancer based on the fluorescence of 5-aminolaevulinic acid hexylester-induced protoporphyrin IX: a pilot study, Brit J Cancer, 80 (1999) 185-193.

[3] P. Hillemanns, H. Weingandt, R. Baumgartner, J. Diebold, W. Xiang, H. Stepp, Photodetection of cervical intraepithelial neoplasia using 5aminolevulinic acid-induced porphyrin fluorescence, Cancer-Am Cancer Soc, 88 (2000) 2275-2282.

[4] Q.T. Nguyen, R.Y. Tsien, Fluorescence-guided surgery with live molecular navigation - a new cutting edge, Nat Rev Cancer, 13 (2013) 653-662.

[5] M.J. Colditz, R.L. Jeffree, Aminolevulinic acid (ALA)-protoporphyrin IX fluorescence guided tumour resection. Part 1: Clinical, radiological and pathological studies, J Clin Neurosci, 19 (2012) 1471-1474.

[6] T. Ohmura, T. Fukushima, H. Shibaguchi, S. Yoshizawa, T. Inoue, M. Kuroki, K. Sasaki, S.I. Umemura, Sonodynamic Therapy with 5-Aminolevulinic Acid and Focused Ultrasound for Deep-seated Intracranial Glioma in Rat, Anticancer Res, 31 (2011) 2527-2533.

[7] H.J. Chen, X.B. Zhou, Y. Gao, B.Y. Zheng, F.X. Tang, J.D. Huang, Recent progress in development of new sonosensitizers for sonodynamic cancer therapy, Drug Discov Today, 19 (2014) 502-509.

[8] B. Nokes, M. Apel, C. Jones, G. Brown, J.E. Lang, Aminolevulinic acid (ALA): photodynamic detection and potential therapeutic applications, J Surg Res, 181 (2013) 262-271.

[9] D.E.J.G.J. Dolmans, D. Fukumura, R.K. Jain, Photodynamic therapy for cancer, Nat Rev Cancer, 3 (2003) 380-387.

[10] C. Chi, Y. Du, J. Ye, D. Kou, J. Qiu, J. Wang, J. Tian, X. Chen, Intraoperative imaging-guided cancer surgery: from current fluorescence molecular imaging methods to future multi-modality imaging technology, Theranostics, 4 (2014) 1072-1084.

[11] A. Omuro, L.M. DeAngelis, Glioblastoma and Other Malignant Gliomas A Clinical Review, Jama-J Am Med Assoc, 310 (2013) $1842-1850$.

[12] J.T. Huse, E.C. Holland, Targeting brain cancer: advances in the molecular pathology of malignant glioma and medulloblastoma, Nat Rev Cancer, 10 (2010) 319-331.

[13] W. Stummer, U. Pichlmeier, T. Meinel, O.D. Wiestler, F. Zanella, H.J. Reulen, A.L.-G.S. Group, Fluorescence-guided surgery with 5-aminolevulinic acid for resection of malignant glioma: a randomised controlled multicentre phase III trial, The Lancet. Oncology, 7 (2006) $392-401$.

[14] W. Stummer, H.J. Reulen, T. Meinel, U. Pichlmeier, W. Schumacher, J.C. Tonn, V. Rohde, F. Oppel, B. Turowski, C. Woiciechowsky, K. Franz, T. Pietsch, A.L.-G.S. Group, Extent of resection and survival in glioblastoma multiforme: identification of and adjustment for bias, Neurosurgery, 62 (2008) 564-576; discussion 564-576.

[15] M. Hefti, H.M. Mehdorn, I. Albert, L. Dorner, Fluorescence-Guided Surgery for Malignant Glioma: A Review on Aminolevulinic Acid Induced Protoporphyrin IX Photodynamic Diagnostic in Brain Tumors, Curr Med Imaging Rev, 6 (2010) 254-258.

[16] J.T. Dalton, C.R. Yates, D.H. Yin, A. Straughn, S.L. Marcus, A.L. Golub, M.C. Meyer, Clinical pharmacokinetics of 5-aminolevulinic acid in healthy volunteers and patients at high risk for recurrent bladder cancer, J Pharmacol Exp Ther, 301 (2002) 507-512.

[17] C. Perotti, A. Casas, H. Fukuda, P. Sacca, A. Batlle, ALA and ALA hexyl ester induction of porphyrins after their systemic administration to tumour bearing mice, Brit J Cancer, 87 (2002) 790-795.

[18] L. Rodriguez, A. Batlle, G. Di Venosa, A.J. MacRobert, S. Battah, H. Daniel, A. Casas, Study of the mechanisms of uptake of 5-aminolevulinic acid derivatives by PEPT1 and PEPT2 transporters as a tool to improve photodynamic therapy of tumours, Int J Biochem Cell B, 38 (2006) 1530-1539.

[19] N. Fotinos, M.A. Campo, F. Popowycz, R. Gurny, N. Lange, 5-Aminolevulinic acid derivatives in photomedicine: Characteristics, application and perspectives, Photochem Photobiol, 82 (2006) 994-1015.

[20] F. L'Eplattenier H, B. Klem, E. Teske, F.J. van Sluijs, S.A. van Nimwegen, J. Kirpensteijn, Preliminary results of intraoperative photodynamic therapy with 5-aminolevulinic acid in dogs with prostate carcinoma, Veterinary journal, 178 (2008) 202-207. 
[21] B. Elfsson, I. Wallin, S. Eksborg, K. Rudaeus, A.M. Ros, H. Ehrsson, Stability of 5-aminolevulinic acid in aqueous solution, Eur J Pharm Sci, 7 (1999) $87-91$.

[22] M. Novo, G. Huttmann, H. Diddens, Chemical instability of 5-aminolevulinic acid used in the fluorescence diagnosis of bladder tumours, J Photoch Photobio B, 34 (1996) 143-148.

[23] Y. Berger, A. Greppi, O. Siri, R. Neier, L. Juillerat-Jeanneret, Ethylene glycol and amino acid derivatives of 5-aminolevulinic acid as new photosensitizing precursors of protoporphyrin IX in cells, J Med Chem, 43 (2000) 4738-4746.

[24] Y. Berger, L. Ingrassia, R. Neier, L. Juillerat-Jeanneret, Evaluation of dipeptide-derivatives of 5-aminolevulinic acid as precursors for photosensitizers in photodynamic therapy, Bioorgan Med Chem, 11 (2003) 1343-1351.

[25] F. Giuntini, L. Bourre, A.J. MacRobert, M. Wilson, I.M. Eggleston, Improved Peptide Prodrugs of 5-ALA for PDT: Rationalization of Cellular Accumulation and Protoporphyrin IX Production by Direct Determination of Cellular Prodrug Uptake and Prodrug Metabolization, J Med Chem, 52 (2009) 4026-4037.

[26] J.L. Millan, W.H. Fishman, Biology of Human Alkaline-Phosphatases with Special Reference Ts Cancer, Crit Rev Cl Lab Sci, 32 (1995) 1-39.

[27] J. Bukowczan, S. Pattman, F. Jenkinson, R. Quinton, Regan isoenzyme of alkaline phosphatase as a tumour marker for renal cell carcinoma, Ann Clin Biochem, 51 (2014) 611-614.

[28] A. Chaux, E. Comperat, J. Varinot, J. Hicks, K. Lecksell, J. Solus, G.J. Netto, High Levels of Phosphatase and Tensin Homolog Expression Are Associated With Tumor Progression, Tumor Recurrence, and Systemic Metastases in pT1 Urothelial Carcinoma of the Bladder: A Tissue Microarray Study of 156 Patients Treated by Transurethral Resection, Urology, 81 (2013) 116-122.

[29] A.A.N.P.M. Dabare, A.M.E. Nouri, H. Cannell, T. Moss, A.K. Nigam, R.T.D. Oliver, Profile of placental alkaline phosphatase expression in human malignancies: Effect of tumour cell activation on alkaline phosphatase expression, Urol Int, 63 (1999) 168-174.

[30] E.Y. Yu, F. Saad, A. Londhe, N.D. Shore, H. Van Poppel, D.E. Rathkopf, M.R. Smith, C. Logothetis, P.L. De Souza, K. Fizazi, P.F.A. Mulders, P.N Mainwaring, J.D. Hainsworth, T.M. Beer, S.A. North, E.J. Small, H.I. Scher, T.W. Griffin, M.K. Yu, C.J. Ryan, Association of alkaline phosphatase (ALP) with clinical outcomes in chemotherapy-naive patients (pts) with metastatic castration-resistant prostate cancer (mCRPC): Results from COU-AA-302, J Clin Oncol, 32 (2014)

[31] A. Casas, A.M. Batlle, A.R. Butler, D. Robertson, E.H. Brown, A. MacRobert, P.A. Riley, Comparative effect of ALA derivatives on protoporphyrin IX production in human and rat skin organ cultures, Br J Cancer, 80 (1999) 1525-1532.

[32] J.C. Sheehan, V.S. Frank, Peptide Syntheses Using Energy-Rich Phosphorylated Amino Acid Derivatives, J Am Chem Soc, 72 (1950) $1312-1316$

[33] J. Kloek, G.M.J.B. vanHenegouwen, Prodrugs of 5-aminolevulinic acid for photodynamic therapy, Photochem Photobiol, 64 (1996) $994-1000$.

[34] E.K. Jaffe, The porphobilinogen synthase catalyzed reaction mechanism, Bioorg Chem, 32 (2004) 316-325.

[35] A. Alouane, R. Labruere, T. Le Saux, F. Schmidt, L. Jullien, Self-Immolative Spacers: Kinetic Aspects, Structure-Property Relationships, and Applications, Angew Chem Int Edit, 54 (2015) 7492-7509.

[36] O.B. Gadmar, J. Moan, E. Scheie, L.W. Ma, Q. Peng, The stability of 5-aminolevulinic acid in solution, J Photoch Photobio B, 67 (2002) 187-193.

[37] J.L. Millan, Alkaline Phosphatases : Structure, substrate specificity and functional relatedness to other members of a large superfamily of enzymes, Purinergic signalling, 2 (2006) 335-341.

[38] Z. Luksiene, I. Eggen, J. Moan, J.M. Nesland, Q. Peng, Evaluation of protoporphyrin IX production, phototoxicity and cell death pathway induced by hexylester of 5-aminolevulinic acid in Reh and HPB-ALL cells, Cancer Lett, 169 (2001) 33-39.

[39] E.S. Chu, T.K. Wong, C.M. Yow, Photodynamic effect in medulloblastoma: downregulation of matrix metalloproteinases and human telomerase reverse transcriptase expressions, Photochemical \& photobiological sciences : Official journal of the European Photochemistry Association and the European Society for Photobiology, 7 (2008) 76-83.

[40] H. Nishigori, M. Mizumura, M. Iwatsuru, The hen's fertile egg screening test (HEST): a comparison between the acute toxicity for chick embryos and rodents of 20 drugs, Cell biology and toxicology, 8 (1992) 255-265.

[41] N. De Magalhaes, L.H. Liaw, M. Berns, V. Cristini, Z. Chen, D. Stupack, J. Lowengrub, Applications of a new In vivo tumor spheroid based shell-less chorioallantoic membrane 3-D model in bioengineering research, Journal of biomedical science and engineering, 3 (2010) 20-26.

[42] A. Ivascu, M. Kubbies, Rapid generation of single-tumor spheroids for high-throughput cell function and toxicity analysis, J Biomol Screen, 11 (2006) 922-932. 
<smiles>[R1]OC(=O)CCC(=O)CNC(=O)OCO[PH]([O-])([O-])[O-]</smiles>

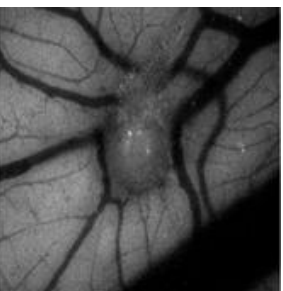

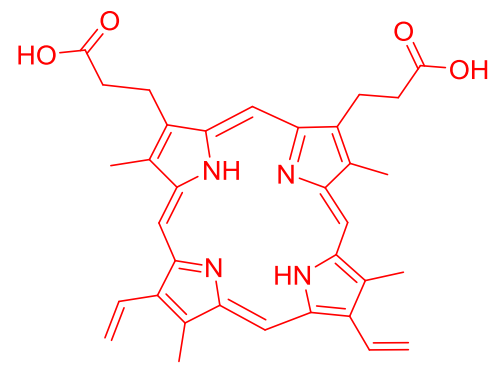

tumor photodetection

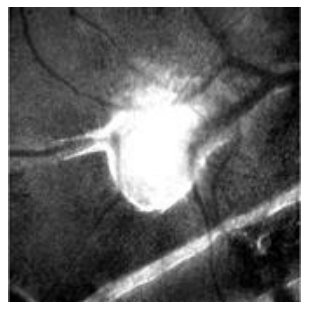

